\title{
inscuteable and numb mediate asymmetric muscle progenitor cell divisions during D rosophila myogenesis
}

\author{
Ana Carmena, 1,3 Bernadette Murugasu-Oei, ${ }^{2,3}$ Devi Menon, ${ }^{2}$ Fernando Jiménez, ${ }^{1}$ \\ and William Chia ${ }^{2,4}$ \\ ${ }^{1}$ Centro de Biologia M olecular "Severo Ochoa," C.S.I.C.-Universidad Autonoma, 28049 Madrid, Spain; ${ }^{2}$ Institute \\ of Molecular and Cell Biology, N ational University of Singapore, Singapore
}

\begin{abstract}
Each larval hemisegment comprises $\sim 30$ uniquely specified somatic muscles. These derive from muscle founders that arise as distinct sibling pairs from the division of muscle progenitor cells. We have analyzed the progenitor cell divisions of three mesodermal lineages that generate muscle (and pericardial cell) founders. Our results show that Inscuteable and Numb proteins are localized as cortical crescents on opposite sides of dividing progenitor cells. Asymmetric segregation of Numb into one of the sibling myoblasts depends on inscuteable and is essential for the specification of distinct sibling cell fates. Loss of numb or inscuteable results in opposite cell fate transformations-both prevent sibling myoblasts from adopting distinct identities, resulting in duplicated or deleted mesodermal structures. Our results indicate that the muscle progenitor cell divisions are intrinsically asymmetric; moreover, the involvement of both inscuteable and numb/ $\mathrm{N}$ suggests that the specification of the distinct cell fates of sibling myoblasts requires intrinsic and extrinsic cues.
\end{abstract}

[Key Words: Myogenesis; asymmetric cell division; muscle progenitor]

Received September 18, 1997; revised version accepted December 4, 1997.

The Drosophila larva is capable of an extraordinary repertoire of movements made possible through a complex array of muscles that attach to its body wall. Each of the 30 larval somatic muscles found reiterated hemisegmentally possesses a distinct identity characterized by specific size, shape, pattern of gene expression, insertion sites and innervation (for review, see Bate 1993). It has been proposed that each muscle derives from a cell that is uniquely endowed with information to act as a "seed" or founder for the assembly of that muscle (Bate 1990; Dohrmann et al. 1990). As the founder fuses with neighboring unspecified myoblasts it imparts its informational content to the other nuclei within the syncytia, thereby entraining them to a similar differentiation program. Two lines of evidence support this founder hypothesis (Bate 1990). First, an increasing number of putative transcription factors, such as S59 (D ohrmann et al. 1990), Apterous (Bourgouin et al. 1992), Even-skipped [(Eve) Frasch et al. 1987], Vestigial (Bate et al. 1993), Krüppel [(Kr) this work; Ruiz-Gomez et al. 1997], and $\mathrm{N}$ autilus (Michelson et al. 1990), have been found that are expressed initially in the nuclei of a subset of myoblasts and thereafter in subsets of syncytia derived from these cells. As the marker-expressing cell fuses with ad-

\footnotetext{
${ }^{3}$ These authors contributed equally to this work.

${ }^{4}$ Corresponding author.

E-MAIL MCBWCHIA@MCB.NUS.EDU.SG; FAX (65) 7791119.
}

jacent non-marker-expressing myoblasts, the nuclei of the newly recruited cells are induced into marker expression (Carmena et al. 1995; Rushton et al. 1995). The expression patterns of these genes suggest that they may act as muscle identity genes specifying distinct muscles. Second, in mutations where myoblast fusion fails, the initial expression patterns of these putative identity genes appear unaltered, but induction of marker expression in the nuclei of neighboring myoblasts does not occur (Rushton et al. 1995). However, a subset of myoblasts still succeeds in attaching to the correct sites and generally taking on characteristics typical for a mature muscle occupying the same position in a normal embryo. This special class of myoblasts seen in fusion-defective mutants appears to have the necessary information content to seed the formation of specific muscles and presumably represents muscle founders. Taken together, these observations suggest that the critical steps in myogenesis leading to the patterning of the somatic musculature are the formation of muscle founders at precise locations within the mesoderm and the correct specification of their fates.

The mesodermal primordium arises from the ventral domain of the blastoderm and is characterized by the uniform expression of the bHLH-type transcription factor Twist (Twi, Thisse et al. 1988). During gastrulation these cells invaginate and spread as a layer under the ectoderm to form the mesoderm. At this stage, these 
cells are restricted to form mesodermal derivatives but are not yet committed to differentiate towards any particular mesodermal cell type. Various studies have shown that the subsequent specification of the mesoderm requires non-autonomous inputs [e.g., Decapentapl egic (Dpp), Wingless (Wg), and Hedgehog (Hh)] from the ectoderm and that the initial subdivisions result in the delineation of relatively broad domains (StaehlingHampton et al. 1994; Baker and Schubiger 1995; Baylies et al. 1995; Frasch 1995; Ranganayakulu et al. 1996). The first sign of subdivision within the mesoderm is seen when the Twi expression pattern changes from being uniform to one comprising of segmentally repeated high and low expression domains-the high Twi-expressing region demarcates the primordia of the somatic musculature, whereas the low Twi-expressing domain gives rise to the visceral and cardiac muscles (Dunin Borkowski et al. 1995; Baylies and Bate 1996). Further subdivision is manifested through the sequential expression of the proneural gene lethal of scute (I'sc) in 19 clusters of cells within each domain of high Twi expression (Carmena et al. 1995). In a process reminiscent of neuroblast segregation and similarly requiring the neurogenic genes (Corbin et al. 1991; Bate et al. 1993; Carmena et al . 1995), one (or, less often, two) cell from each cluster retains high levels of L'sc and expresses a particular subset of putative identity genes. This cell has been defined as a progenitor. It moves into close contact with the ectoderm and divides once to produce two daughter cells.

Although many of the mesodermal lineages have not been elucidated, the available information on the daughters of progenitors indicates that each sibling becomes a founder for a particular larval muscle, an adult muscle precursor, or a cell of hitherto unknown fate (this study; Carmena et al. 1995). These observations suggest that the si bling myoblasts acquire distinct fates and led us to suspect that progenitors in the mesoderm might undergo asymmetric cell division. If this were so, what factors might be involved in establishing this asymmetry?

A number of genes have been implicated in asymmetric cell divisions in the nervous system of Drosophila. The membrane-associated protein $\mathrm{N} \mathrm{umb}(\mathrm{N} b)$ (Uemura et al. 1989) localizes basally in neural progenitors and segregates preferentially into one of two daughter cells (Rhyu et al. 1994; Knoblich et al. 1995; Spana et al. 1995; Kraut et al. 1996). In the PN S (Guo et al. 1996) and in the midl ine precursor M P2 (Spana and Doe 1996) where nb is essential for the development of distinct sibling identities, $\mathrm{N} \mathrm{b}$ acts by supressing $\mathrm{N}$ otch ( $\mathrm{N}$ ) signaling (for review on N, see Artavanis-T sakonas et al. 1995). Mutations in nb cause defects in the larval muscle pattern (Uemura et al. 1989; Rhyu et al. 1994); however, as N b was not known to be expressed in the mesoderm, the underlying reasons for these defects were unclear. A homeodomain protein Prospero (Pros) localizes basally in neuroblasts, segregates preferentially into one sibling, and plays a role in neural cell fate decisions in the CNS (Hirata et al. 1995; Knoblich et al. 1995; Spana and Doe 1995). However, a role for pros in the specification of larval muscles is unlikely, as pros mutants exhibit a wild-type larval muscle pattern (Broadie and Bate 1993). The apically localized protein Inscuteable (Insc) (Kraut and Campos-Ortega 1996) has been described as an organizer of asymmetric cell divisions for neuroblasts and a subset of the ectodermal cells of the procephalic region (Kraut et al. 1996). The asymmetric local ization and segregation of $\mathrm{Nb}$, Pros, and pros $\mathrm{RN} \mathrm{A}$, as well as the apical / basal orientation of the mitotic spindle in neuroblasts, all require insc ( $\mathrm{Li}$ et al. 1997). A role for insc in muscle development is indicated by the recent finding (Knirr et al. 1997; M. Zavortink, unpubl.) that insc is allelic to the previously described muscle patterning gene not enough muscles (Burchard et al. 1995).

In this study we foll owed the fate of three progenitors in the mesoderm and show data suggesting that they give rise to two dorsal muscles and a subset of pericardial cells in the Drosophila Iarva. In all three cases, the progenitors undergo asymmetric cell division as evidenced by the asymmetric localization of Insc and N b to opposite poles in the progenitors and the preferential segregation of $\mathrm{N} \mathrm{b}$ into only one of the siblings produced upon progenitor cell division. Furthermore, loss of insc or nb causes the opposite sibling cell fate transformations, which manifests as duplication or loss of mature mesodermal structures. These findings define events that occur between the selection of progenitors from relatively large subdomains of the mesoderm and the specification of their progeny that become founders that pattern the mesoderm. Our results suggest that in addition to extrinsic cues, intrinsic factors inherited as a consequence of lineage are utilized for the assignation of distinct cell fates to muscle founders and precursors of pericardial cells.

\section{Results}

We have foll owed the fate of the progenitors P2, P15, and P17 (see Carmena et al. 1995) in the wild-type embryo, using several markers. Our results suggest that each of these progenitors divides once at a specific stage in development to give rise to the founders for the $\mathrm{Eve}^{+}$pericardial cells (EPCs), the $\mathrm{Eve}^{+} \mathrm{Kr}^{+}$dorsal acute 1 (DA1 $=\mathrm{m} 1$ ) muscle, and the $\mathrm{Kr}^{+}$dorsal oblique 1 (DO1 =m9) muscle, respectively, and a sibling cell of unknown fate (see Fig. 1). We chose to examine these progenitors because mutations in insc and $\mathrm{nb}$ have strong effects on the development of the EPC as well as DA 1 and DO1 and suitable markers are avail able for the analyses of these cells and the division of their progenitors.

Insc is asymmetrically localized as cortical crescents, but without a fixed orientation, in progenitors in the mesoderm

Insc protein is observed in some large Twi-positive cells in the mesoderm that undergo mitosis (data not shown), suggesting that Insc may be expressed in muscle progenitors. Double labeling experiments with antibodies 


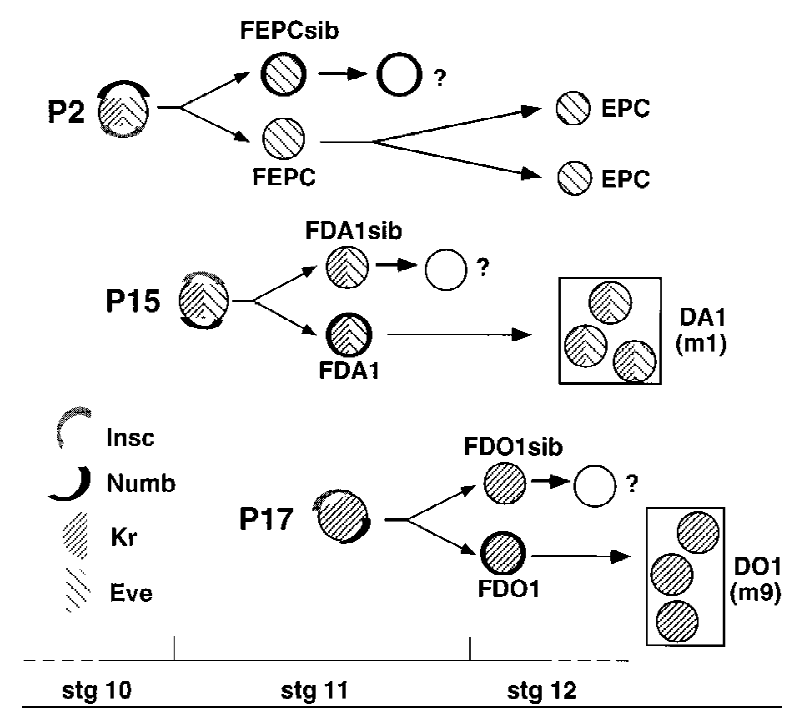

Figure 1. Three progenitors and their mesodermal derivatives. $\mathrm{P} 2, \mathrm{P} 15$, and P17 can be identified using anti-Kr and/or anti-Eve. Each local izes Insc (gray) and $\mathrm{N} \mathrm{b}$ (black) as crescents on opposite sides of the cell cortex just before division and divides to produce two sibling cells only one of which inherits $\mathrm{N} \mathrm{b}$. In the case of $\mathrm{P} 2$, it is the $\mathrm{N} \mathrm{b}^{-}$progeny that retains Eve expression, becomes the founder of the Eve ${ }^{+}$pericardial cells (FEPC), and divides to generate the EPC. Its $\mathrm{N} \mathrm{b}^{+}$sibling (FEPCsib) initially expresses Eve but soon extinguishes marker expression and its fate is unknown. For $\mathrm{P} 15$ and $\mathrm{P} 17$, the $\mathrm{N} \mathrm{b}^{+}$daughter cell retains marker expression and become founders (FDA 1 and FDO1) for the muscle DA $1(=\mathrm{m} 1)$ and the muscle DO1 $(=\mathrm{m} 9)$, respectively. Their $\mathrm{N} \mathrm{b}^{-}$siblings (FDA 1sib and FDO1sib) extinguish marker expression and their fates are unknown. The stages during development when these cells can be detected and the schematic representations used for $\mathrm{Kr}$, Eve, $\mathrm{N} \mathrm{b}$, and Insc are indicated. Our lineage model is based on a careful analysis of wild-type embryos at different stages with several markers.

against Insc and L'sc revealed that Insc is expressed as cortical crescents in a number of muscle progenitors, including P15 and P17, as well as P2-the EPC progenitor (Fig. 2A-E). Results from double staining experi- ments with anti-Insc and a DNA-binding dye (Lundell and Hirsh 1994) indicate that the local ization of Insc as a cortical crescent occurs during mitosis (Fig. 2F). InsC expression appears to occur specifically in the progenitors and has not been seen in their postmitotic progeny. In contrast to the nervous system where Insc protein crescents are localized to the apical cortex of neuroblasts (Kraut et al. 1996; Kraut and Campos-Ortega 1996), there does not appear to be a fixed orientation for the Insc crescent in the different progenitors of the mesoderm (Fig. 2A-F). This appears to be due to the fact that unlike neuroblasts that align their mitotic spindles al ong the apical / basal axis, these progenitors do not divide with a fixed orientation. However, for any given type of progenitor (e.g., P17), the Insc crescent accumulates at a similar position relative to the anterior/posterior or dorsal / ventral axis (Fig. 2B). Despite these differences in the orientation of the Insc crescent, there appears to be a tight correlation between the position of the Insc protein crescent and the orientation of the progenitor cell division as deduced from the staining of DNA; the location of the Insc crescent appears to center on one of the mitotic spindle poles (Fig. 2F).

Numb localizes as a cortical crescent on the opposite side to Insc and its asymmetric localization and segregation requires insc

$\mathrm{Nb}$ expression can be seen throughout the mesoderm (Fig. 3A) with higher levels in the high Twi-expressing domain that gives rise to the somatic muscles (Bate 1993). This generalized expression appears to be localized to the cortex of all mesodermal cells. Double-labeling experiments with anti-Eve and anti- $\mathrm{Nb}$ as well as anti-Kr and anti-N b indicate that cortical crescents of $\mathrm{N}$ b protein can be seen in progenitor cells (Fig. 3A,B), including P2, P15 (see Fig. 5, below) and P17 (Fig. 3C). Again, in contrast to the $\mathrm{Nb}$ crescents found in mitotic neuroblasts, which are al ways on the basal cortex, the $\mathrm{N} \mathrm{b}$ crescents in the progenitors of the mesoderm do not localize in a specific orientation (e.g., compare positions

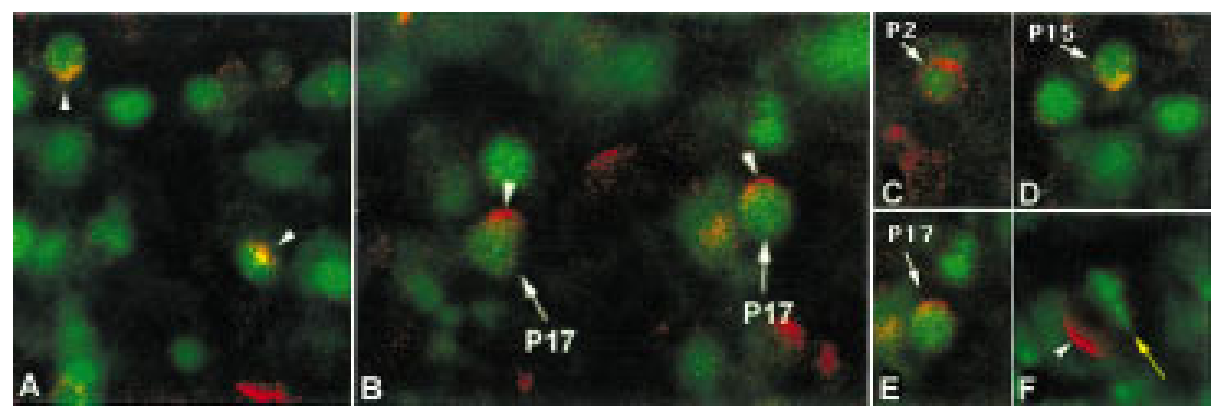

Figure2. Insc protein accumulates as cortical crescents in progenitors of the mesoderm. Embryos were stained for Insc (red) and either L'sC (A, C-E, green), $\mathrm{Kr}$ (B, green), or DN A ( $F$, green). Anterior is left and dorsal is up in all panels. Insc crescents in muscle progenitors do not have a fixed orientation (see arrowheads in A showing Insc crescents in two different progenitors within a hemisegment) but local ize to similar positions in a given type of progenitor (B, cf. arrowheads showing Insc crescents in P17 in two adjacent hemisegments). All three progenitors analyzed in this study, P2, P15, and P17, enlarged their nuclei and display Insc crescents shortly before division (arrows in C-E). (F) A metaphase progenitor stained for Insc (arrowhead) and DN A (yellow arrow) to show the location of the Insc crescent relative to (the deduced orientation of) the mitotic spindle. 

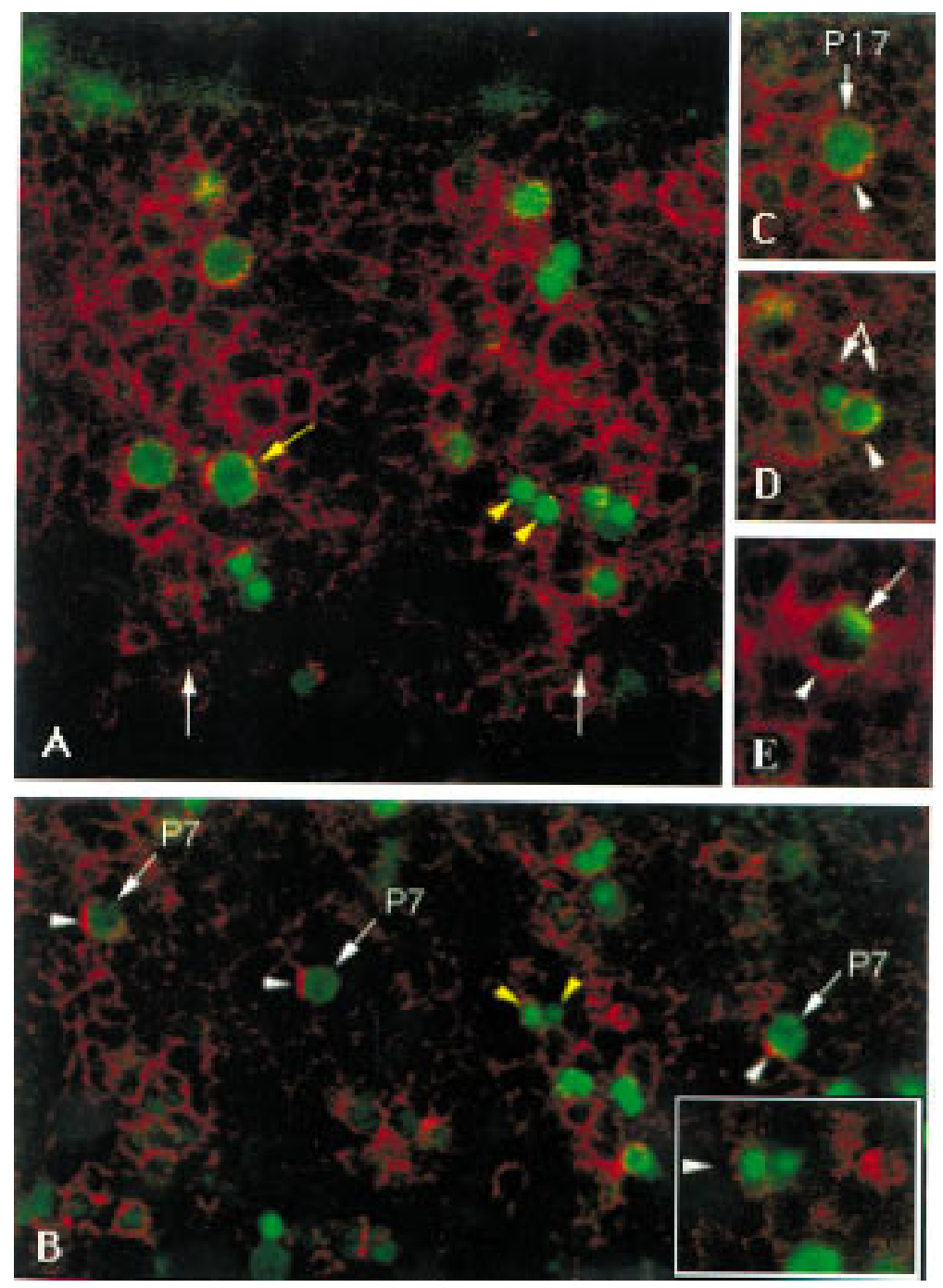

Figure 3. Numb protein becomes polarized in muscle progenitors and segregates preferentially with one of the two progeny cells. Embryos were stained for $\mathrm{Nb}$ (red) and either $\mathrm{Kr}$ (A-D, green) or Insc ( $E$, green). Anterior is left and dorsal is up in all panels. (A) A lateral view of two hemisegments of the mesoderm. Each hemisegment contains a domain of high $\mathrm{Nb}$ expression (white arrows) from which progenitors segregate. Some progenitors express $\mathrm{Kr}$, and their nuclei enlarge as they enter mitosis (yellow arrow). $\mathrm{Kr}$ is also detected in pairs of postmitotic cells (yellow arrowheads), derived from recently divided progenitors. (B) P7 in hemisegments 1,2 , and 4 (from left to right) showing $\mathrm{Nb}$ crescents (white arrowheads) at the anterior half of each of these progenitors. In hemisegment 3, P7 has al ready divided and the two sibling progeny (yellow arrowheads) can be better seen at a deeper plane of focus (see inset); the progeny placed anteriorly has inherited $\mathrm{Nb}$. (C) Polarization of $\mathrm{Nb}$ as a cortical crescent (arrowhead) in P17 as it begins to divide. (D) After division, the two progeny cells of P17 (arrows) still express $\mathrm{Kr}$. However, the cell that has presumably inherited parental $\mathrm{Nb}$ (arrowhead) retains higher levels of $\mathrm{Kr}$ than its $\mathrm{Nb}^{-}$sibling. (E) The $\mathrm{Nb}$ cortical crescent (arrowhead) is located opposite the Insc cortical crescent (arrow) in muscle progenitors. of the $\mathrm{N} \mathrm{b}$ crescents seen in progenitors in Fig. $3 \mathrm{~A}-\mathrm{C}$ ). As with the localization of the Insc cresent, the position of the $\mathrm{N} \mathrm{b}$ crescent appears to be similar for a given progenitor type (Fig. 3B). Moreover, the $\mathrm{Nb}$ crescent is always present on the side opposite to the Insc crescent (Fig. 3E). When the progenitor cells divide, $\mathrm{Nb}$ protein is asymmetrically partitioned into only one of the two progeny (Fig. 3D; also see Fig. 5, below). In the absence of insc function, $\mathrm{N}$ b is al ways distributed throughout the cortex of dividing progenitor cells and the protein is distributed to both progeny (see Fig. 5G-J, below). Hence, both the asymmetric localization in progenitors and the preferential segregation of $\mathrm{Nb}$ to only one daughter cell are dependent on insc. In contrast, Insc protein distribution in progenitors of the mesoderm is unaffected in nb mutant embryos (not shown).

\section{Loss of nb or insc causes opposite mesodermal} phenotypes

To assess whether the expression of insc and nb in progenitors and the asymmetric segregation of $\mathrm{Nb}$ to one progeny cell reflect an underlying role for these molecules in the mesoderm, we examined the terminal phenotypes in loss-of-function mutations of insc or nb. Embryos homozygous for $\mathrm{nb}^{3}$, a putative amorphic allele, were stained with anti-myosin heavy chain ( $\mathrm{MHC}$ ), which labels all somatic muscles, and anti-Eve, which stains DA 1 and EPC (Fig. 4A shows a wild-type staining pattern). The loss of $n b$ has a general effect causing many of the dorsal and ventral somatic muscles to be lost (data not shown). However, the expressivity of the phenotype varies for each muscle and not all somatic muscles are affected. N everthel ess, in $\mathrm{nb}^{3}$ homozygotes, DA 1 is almost always absent, whereas DO1 is lost from $>50 \%$ of the mutant hemisegments. In contrast, the number of EPC is increased (Fig. 4B; T able 1). Si milar defects (al beit with a slightly lower expressi vity) were obtained for embryos homozygous for $\mathrm{nb}^{1}$ (T able 1 ).

Embryos homozygous for two different insc null alleles were analyzed in a similar way. For insc ${ }^{\mathrm{P} 9}$ homozygotes, a number of somatic muscles, including DA 1 and the dorsal oblique muscles, as well as the EPC, were 
(A.) AB44 (wild-type)
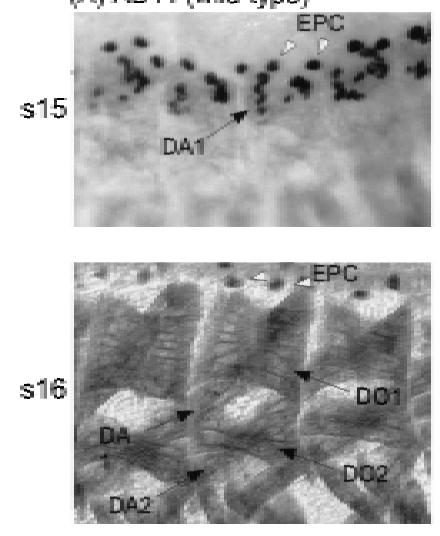

(B) numbra ${ }^{3}$
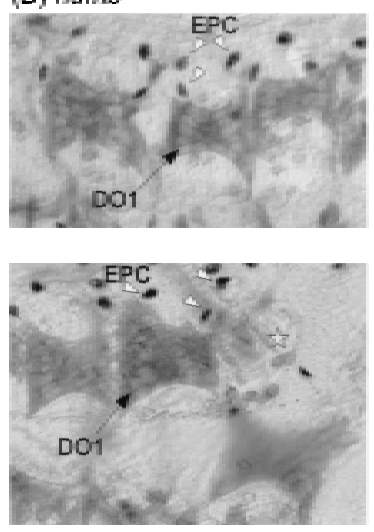

(C) inst P49
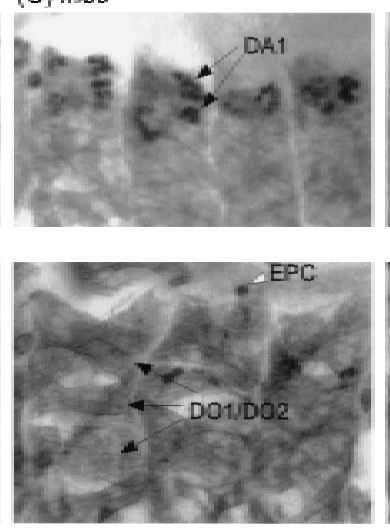

(D) twist-ga/4, UAS-numb
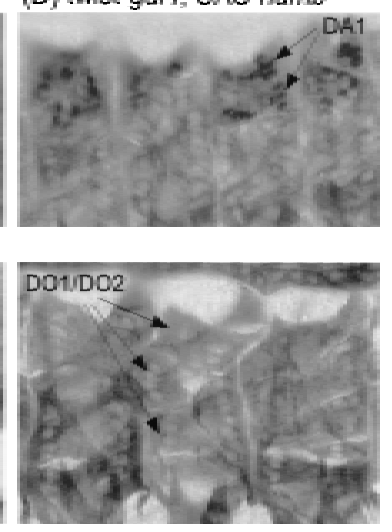

(E) inse P49; hsp 70-insc

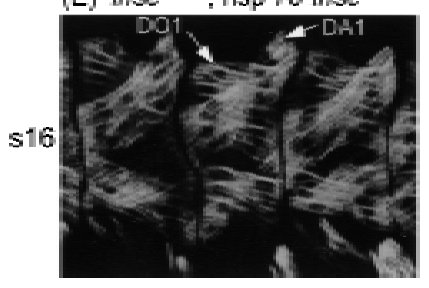

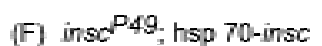

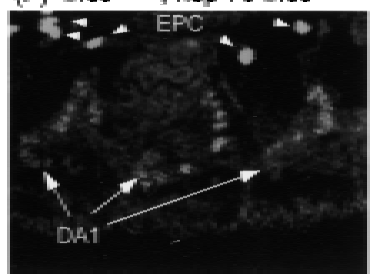

(G) insc ${ }^{49}$ numb $^{3}$

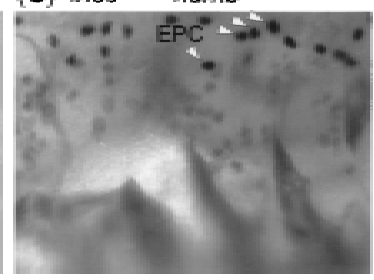

Figure 4. The effects of various genotypes on the number of EPCS, DA 1s, and DO1S. (A-D,G) Embryos were double stained for Eve (black nuclear stain) and M HC (stains all muscles) using horseradish peroxidase-conjugated secondary antibodies. (AB44) The P-lacZ insertion from which insc ${ }^{\mathrm{P} 49}$ and insc $\mathrm{P}^{\mathrm{72}}$ excisions were generated, showed little muscle defects and was used to represent wild type. The EPCs express Eve from stage 12 onward, and there are usually two per hemisegment in wild type (A). Their numbers increase in $\mathrm{nb}$ embryos (B) and in the insc,nb double mutant (G). In insc embryos (C) and in embryos overexpressing N b (D), a significant reduction of EPC is seen. Because Eve expression in DA1 diminishes after stage 15, embryos at stages 14-15 were used for scoring this muscle (see top panels for DA 1s). Additional DA 1s are seen in insc mutants and in embryos overexpressing $\mathrm{N}$ b, whereas they are essentially el iminated in $\mathrm{nb}^{3}$ embryos. In the insc, nb double mutant, there is a complete loss of all dorsal muscles, DA 1, DO1, DA 2 (m2), and DO2 (m10), as seen by the absence of MHC-stained somatic muscles in the dorsal region at stages 15-16 (G). Muscle DO1 was identified by its position at stage 16 . Its numbers were reduced in nb mutants $\left(^{*}\right)$. In contrast, additional dorsal oblique muscles were present in insc and in embryos overexpressing $\mathrm{N} \mathrm{b}$ (bottom panels). However, in such cases, we could not distinguish between DO1 and DO2. (E,F) Confocal images showing insc ${ }^{\mathrm{P} 49}$ embryos where Insc was expressed under the control of the hsp70 promoter. Embryos were stained with anti- $\beta$-galactosidase and either anti-MHC (E) or anti-Eve (F), and mutant embryos homozygous for both insc ${ }^{\mathrm{P} 49}$ and hsp70-insc were identified by the absence of $\beta$-gal actosi dase expression from lacZ-marked bal ancers. The hemisegments shown in $E$ and $F$ exhibit wild-type musculature; in F rescue of the EPC phenotype is seen in all but the middle hemisegment. For quantitation of the various phenotypes, see Table 1. For all panels, anterior is toward the left.

affected (Fig. 4C; Table 1). However, in contrast to the nb mutants, loss of insc caused $\sim 30 \%$ of the hemisegments to produce an extra DA 1 as well as an $\sim 60 \%$ reduction in the number of EPCs. We also observed an extra dorsal oblique muscle in $\sim 40 \%-50 \%$ of the mutant hemisegments but were unable to determine whether the duplicated muscle was DO1 or DO2 in late (stages 15-16) embryos. Results from confocal analyses of earlier stages indicate that in many instances the duplicated muscle is likely to be DO1 (see Fig. 5H, Fig. $6 \mathrm{H}$, below, and later section). Hence, at the level of the terminal phenotype, it appears that the loss of $\mathrm{nb}$ and the loss of insc cause opposite effects. To ascertain that the loss of insc is responsible for the observed phenotype, we demonstrated that the ectopic expression of a full-length insc CDNA driven by a hsp70 promoter (see M aterials and M ethods) can rescue, at least in part, the phenotype of insc ${ }^{\mathrm{P} 49}$ ho- mozygotes (Fig. 4E,F; Table 1). Interestingly (see Discussion), ectopic expression of insc in a wild-type background has no effect on the development of somatic muscles or EPC (not shown).

$\mathrm{nb}$ overexpression causes the opposite phenotype to $\mathrm{nb}$ loss of function

Our results suggest that insc is required in the progenitors of the mesoderm to ensure asymmetric local ization and segregation of $\mathrm{N} \mathrm{b}$ to one daughter cell. $\mathrm{N} \mathrm{b}$ is in turn necessary to specify the identity of that cell, making it different from its sibling, which fails to inherit $\mathrm{Nb}$ (see also the fol lowing section). To ascertain whether $\mathrm{Nb}$ is also sufficient to specify cell fate, we examined the effects of overexpressing $\mathrm{N} \mathrm{b}$ on the development of structures derived from P2, P15, and P17. T argeted expression 
Table 1. Quantification of EPC, DA1, and DO1 in various genotypes

\begin{tabular}{|c|c|c|c|c|}
\hline \multirow[b]{2}{*}{ Fly strain } & \multicolumn{4}{|c|}{ Average number/hemisegment (total no./total no. of hemisegments examined) } \\
\hline & EPC & $\mathrm{DA} 1(\mathrm{ml})$ & DO1 (m9) & DO1/DO2 (m9/m10) \\
\hline AB44 (wild type) & $2.0(193 / 96)$ & $1.0(96 / 96)$ & $1.0(96 / 96)$ & $2.0(192 / 96)$ \\
\hline $\mathrm{nb}^{1}$ & $3.1(311 / 102)$ & $0.3(27 / 102)$ & $0.7(73 / 99)$ & N.D. \\
\hline $\mathrm{nb}^{3}$ & $2.8(718 / 259)$ & $0(11 / 262)$ & $0.5(60 / 123)$ & N.D. \\
\hline insc $^{\mathrm{P} 49}$ & $0.8(55 / 66)$ & $1.3(83 / 66)$ & $\frac{100}{0}$ & $2.4(235 / 100)$ \\
\hline insc $^{\mathrm{P72}}$ & N.D. & N.D. & - & $2.5(249 / 100)$ \\
\hline insc $^{\text {p49 }} ;$ hsp70-insc & $1.4(78 / 56)$ & $1.1(69 / 64)$ & - & $2.1(131 / 64)$ \\
\hline twi-gal4; UAS-nb & $0.1(6 / 113)$ & $1.5(162 / 108)$ & N.D. & N.D. \\
\hline insc $^{P 49} n^{3}$ & $4.4(443 / 100)$ & $0(0 / 80)$ & $0(0 / 80)$ & $0(0 / 80)$ \\
\hline
\end{tabular}

$\overline{E P C}$ and muscles were identified as described in the legend to Fig. 4. (AB44), The P-lacZ insertion from which insc ${ }^{\mathrm{P} 49}$ and insc $^{\mathrm{P} 72}$ excisions were generated, showed no muscle defects and was used to represent wild type. For insc, where additional dorsal oblique muscles were present and it was not possible to distinguish between DO1 and DO2 (m10), the data are presented as the sum of DO1 and DO2. In N b overexpression experiments, the dorsal region was often packed with many extra muscles such that individual dorsal oblique muscle fibers were not al ways distinguishable based on MHC expression alone. (N.D.) N ot done.

of $\mathrm{Nb}$ was performed using a twi-gal4 driver to induce the expression of a UAS-nb transgene throughout the mesoderm (Brand and Perrimon 1993; al so see Materials and Methods). Animals carrying either the twi-gal 4 or UAS-nb transgene al one did not show any abnormalities in the Eve staining pattern (not shown). Our results (Fig. 4D; Table 1) indicate that the overexpression of $\mathrm{N} \mathrm{b}$ can lead to the duplication of DA 1 as well as the loss of EPC, effects that are opposite those caused by the loss of $\mathrm{nb}$. However, because of the multiplicity of extra dorsal muscles associated with this overexpression paradigm, we were unable to score for DO1. These observations are consistent with the notion that $\mathrm{nb}$ can act in a necessary and sufficient manner to specify mesodermal cell fate.

insc and $\mathrm{nb}$ are required for sibling cells derived from progenitor cells in the mesoderm to adopt distinct cellular identities

One can rationalize the insc and nb loss (and gain)-offunction phenotypes in the following way (see Fig. 1): In wild-type embryos, P15 (and P17) would di vide such that one progeny becomes the founder for DA 1 (and DO1), henceforth referred to as FDA1 (and FDO1), as a consequence of inheriting all of the asymmetrically localized $\mathrm{Nb}$ protein. Its sibling cell does not inherit $\mathrm{Nb}$ and adopts an alternative (unknown) fate. In the absence of insc (or when $\mathrm{nb}$ is overexpressed), $\mathrm{N}$ b is no longer asymmetrically distributed so both daughter cells derived from the P15 (and P17) division would inherit Nb and both would adopt an FDA1 (and FDO1) identity at the expense of its sibling. This would lead to the duplication of DA1 (and DO1), which in fact is observed in insc mutants (Fig. 4C; Table 1). In the case of EPC, one would predict that for the wild-type $\mathrm{P} 2$ cell division, it is the progeny that fails to inherit $\mathrm{N} b$ that becomes the FEPC, whereas its sibling (FEPCsib), which inherits $\mathrm{N} \mathrm{b}$, adopts an alternative but unknown fate. Hence, in insc mutants (or when $\mathrm{nb}$ is overexpressed) both of the $\mathrm{P} 2$ progeny will be $\mathrm{N} \mathrm{b}^{+}$and adopt the fate of FEPC sib at the expense of the FEPC, leading to the loss of EPC (see Fig. 4C; Table 1). Conversely, in the absence of $\mathrm{nb}$, both siblings derived from the progenitor cell division would adopt the identity of the sibling, which normally does not inherit $\mathrm{Nb}$. As a result, the opposite cell fate transformations occur leading ultimatel y to the loss of DA 1 and DO1 and the gain of EPC (see Fig. 4B; Table 1).

To test the validity of the above model, we followed the segregation of $\mathrm{Nb}$ and the fate of the sibling cells derived from the P15, P17, and P2 cell divisions in wildtype, insc ${ }^{\mathrm{P} 49}$ and $\mathrm{nb}^{3}$ embryos (Figs. 5 and 6). In wildtype embryos, P15 expresses Kr and Eve and local izes N b as a cortical crescent (Fig. 5A). Shortly after birth, both P15 progeny are $\mathrm{Kr}^{+} \mathrm{Eve}^{+}$but only one inherits asymmetrically localized $\mathrm{Nb}$ (Fig. 5B). The $\mathrm{N} \mathrm{b}^{+}$cell is the FDA 1; it remains $\mathrm{Kr}^{+} \mathrm{Eve}^{+}$(Figs. $5 \mathrm{C}$ and $6 \mathrm{~A}$ ) and fuses with other myoblasts to form the $\mathrm{Kr}^{+} \mathrm{Eve}^{+} \mathrm{DA} 1$ precursor (Fig. 6G); its N b- sibling cell, FDA 1sib, al ways extinguishes $\mathrm{Kr}$ and Eve expression as it matures and its ultimate fate is not known (Fig. 5B,C). In contrast to the wild-type situation, in insc mutant embryos $\mathrm{Nb}$ is distributed throughout the cortex of the dividing P15 and is distributed to both of the P15 progeny (Fig. 5G); both the FDA 1 and FDA 1 sib maintain Eve and $K r$ expression, and both adopt an FDA 1-like identity (Figs. 5H and 6D), leading ultimately to the formation of two $\mathrm{Kr}^{+} \mathrm{Eve}^{+} \mathrm{DA}$ ls (Fig. 6H). In nb mutant embryos, the opposite cell fate transformation occurs. Both of the $\mathrm{P} 15$ progeny are $\mathrm{Kr}^{+}$ $\mathrm{Eve}^{+}$at birth; however, both act like the FDAlsib and extinguish expression of both markers (Fig. 6F, fading yell ow cells), ultimately leading to the failure to form DA 1 (Fig. 6l). Hence, N b is normally segregated only to FDA 1 (not FDA 1sib) and is required to specify its identity. However, if $\mathrm{N} \mathrm{b}$ is present in both cells as the result of removing insc (or overexpressing $\mathrm{N}$ b), it is sufficient to cause the FDA 1sib to adopt a FDA 1 identity.

The situation with the P17 division is analogous to that of P15. In wild type, P17 divides to produce a $\mathrm{Kr}^{+}$ $\mathrm{Nb}^{+}$FDO1 that maintains $\mathrm{Kr}$ expression, and an $\mathrm{Nb}^{-}$ FDO1sib that extinguishes $\mathrm{Kr}$ expression (Figs. 3C-D and $5 \mathrm{C}$ ). In insc mutant embryos, the $\mathrm{Kr}^{+} \mathrm{N} \mathrm{b}^{+}$FDO1 is 


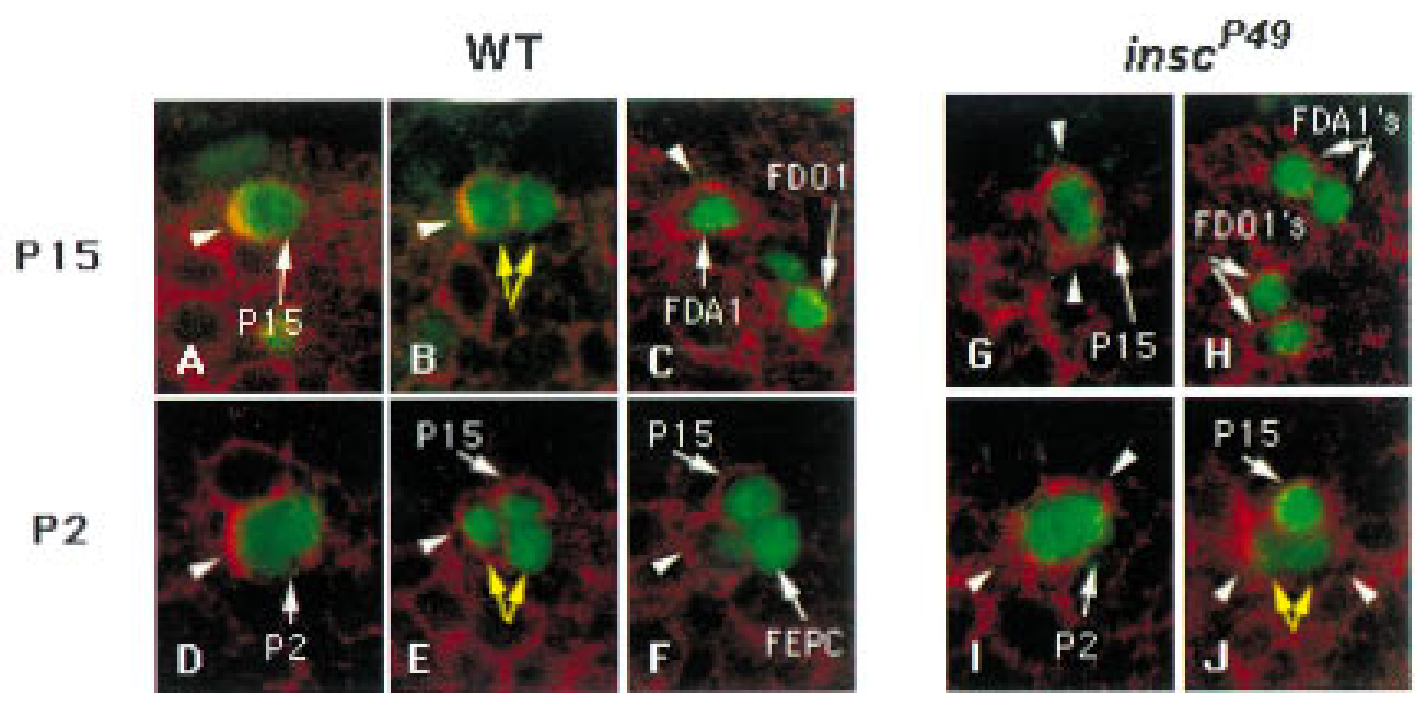

Figure 5. Segregation of $\mathrm{Nb}$ and progression of $\mathrm{Kr}$ expression in the descendants of progenitors in wild-type and insc mutant embryos. Wild-type (A-F) and insc ${ }^{P 49}(G-J)$ embryos were stained for $N$ b (red) and either Kr (green) $(A-C, G, H)$ or Eve (green) (D-F,I J). (A) At early stage 11, a N b crescent (arrowhead) is observed in P15 (arrow), which al so expresses Kr. (B) As P15 divides to give two daughter cells (yellow arrows), $\mathrm{N} \mathrm{b}$ segregates with one of the progeny (arrowhead) that is larger than its sibling. (C) At early stage 12 , Kr is only detected in the descendant from P15 that inherits Nb (FDA 1, arrowhead); its sibling has al ready extinguished Kr expression. The progeny of P17 are also detected. $\mathrm{N}$ ote that $\mathrm{Kr}$ expression is maintained in the $\mathrm{Nb}^{+}$FDO 1 but has al ready decayed considerably in its $\mathrm{Nb}^{-}$sibling. (G) In early stage 11 insc $^{\mathrm{P} 49}$ embryos, $\mathrm{Nb}$ (arrowheads) is not polarized and is distributed throughout the cortex of a dividing P15. $(\mathrm{H})$ In an early stage 12 insc $^{\mathrm{P} 49}$ mutant embryo, siblings derived from P15 and P17 both inherit $\mathrm{N} \mathrm{b}$ and maintain similar high levels of $\mathrm{Kr}$ expression, characteristics of FDA 1 and FDO1, respectively. (D) A N b crescent (arrowhead) in wild-type P2 that expresses Eve as it begins to divide at late stage 10. (E) After P2 divides at early stage 11, N b (arrowhead) segregates with one of the two progeny cells (yellow arrows); at this time, P15, which al so expresses Eve, has been singl ed out but has not yet enlarged. (F) Soon thereafter, Eve expression is extinguished from the $\mathrm{N} \mathrm{b}^{+}$progeny of $\mathrm{P} 2$ (arrowhead). The $\mathrm{N} \mathrm{b}^{-}$sibling (FEPC) is the precursor of the two EPCs. (I) In a insc ${ }^{\mathrm{P} 49}$ embryo, a dividing P2 does not exhibit N b polarization (arrowheads). () Both P2 progeny cells (yellow arrows, just ventral to P15) appear to have inherited N b (arrowheads), and Eve expression is decaying in both cells.

duplicated at the expense of FDO1sib (Fig. 5H), leading to the duplication of DO1 (Fig. 6H). In nb mutant embryos two FDO1sibs are produced at the expense of the FDO1 (Fig. 6F, arrows), which leads to a loss of DO1 (Fig. 6I). It is important to note that our earlier results on the terminal phenotype of insc loss of function does not distinguish between the duplication of DO1 or DO2. The anal yses presented in Figures 5 and 6 confirm that loss of insc causes duplication of DO1 precursors.

In the case of P2 and the EPC, we see a variation from the situation observed with $\mathrm{P} 15$ and P17. $\mathrm{Nb}$ is asymmetrically localized in wild-type P2 (Fig. 5D). When P2 divides, both progeny initially express Eve (Fig. 5E, yellow arrows). However, in contrast to the P15 and P17 cell divisions, the sibling that fails to inherit $\mathrm{N} b$ retains Eve expression and becomes the FEPC; its sibling that inherits $\mathrm{Nb}$ from the progenitor extinguishes Eve expression, and we do not know its ultimate fate (Fig. 5E,F). Our results obtained from following marker expression indicate that the FEPC divides to give two EPC per hemisegment (Fig. 6G). In insc mutant embryos, $\mathrm{Nb}$ is distributed throughout the cortex of the dividing P2 (Fig. 5I). Both progeny are $\mathrm{N} \mathrm{b}^{+}$and $\mathrm{Eve}^{+}$but subsequently extinguish Eve expression (Fig. 5J, yel low arrows), leading ultimately to the loss of EPC (Fig. 6C, H; Table 1). In nb mutant embryos, both of the $\mathrm{P} 2$ progeny retain Eve ex- pression and adopt the identity of the FEPC (Fig. 6E), leading ultimately to the formation of extra EPC (Fig. $6 F, I ;$ T able 1). These results obtained from following the segregation of $\mathrm{Nb}$ and the fate of the progeny cells derived from the P2, P15, and P17 cell divisions support the type of model we propose (see Discussion).

As an aside, as the overall gain of DA1 in the insc mutants is associated with an overall loss of EPC and because both $\mathrm{P} 2$ and $\mathrm{P} 15$ are located in close proximity and express a common marker, it raises the question of whether P2 and P15 might be related by lineage. This is unlikely because on a per hemisegment basis, there appears to be no correlation between the gain of DA 1 and the loss of EPC (data not shown). Furthermore P2 and P15 segregate at different times from distinct L'sc-expressing clusters (see Fig. 1).

insc acts upstream of $\mathrm{nb}$

Because insc and nb mutants show opposite mesodermal phenotypes, we made the double mutant and examined its phenotype to ascertain the hierarchical relationship between insc and nb. The insc, nb double homozygous embryos show loss of DA 1 and DO1, as well as gain of EPC (Fig. 4G). Although qualitatively similar to those shown by nb mutant embryos, the double mutant em- 


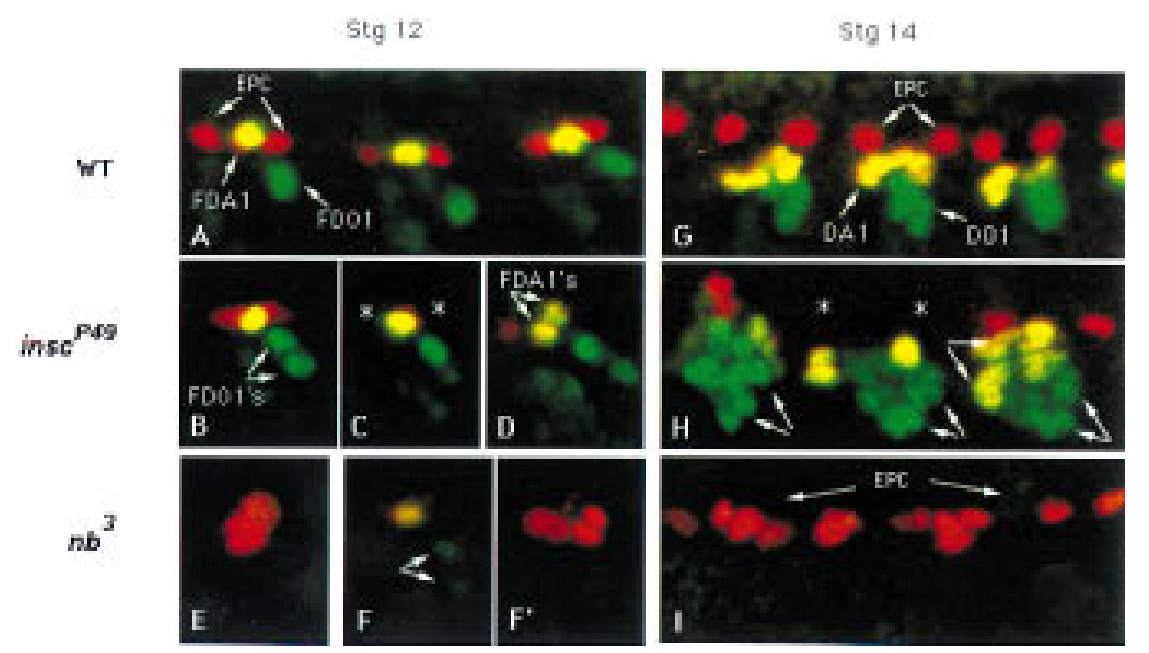

Figure 6. The fate of the progeny from $\mathrm{P} 2$, P15, and P17 progenitors in wild-type, in$\mathrm{sc}^{\mathrm{P} 49}$, and numb ${ }^{3}$ embryos. Embryos were double stained for Eve (red) and $\mathrm{Kr}$ (green). Stage $12\left(\mathrm{~A}-\mathrm{F}^{\prime}\right)$ and stage 14 (G-I) wild-type $(A, G)$, insc ${ }^{P 49}(B-D, H)$, and $n b^{3}\left(E-F^{\prime}, I\right)$ embryos are shown. (A) Three consecutive wild-type hemisegments at mid- to latestage 12. At this stage, the two EPC (red) are al ready present. The $\mathrm{Kr}^{+} \mathrm{Eve}^{+} \mathrm{FDA} 1$ (yellow) and the $\mathrm{Kr}^{+} \mathrm{FDO} 1$ (green) are al so evident. (B-D) In insc ${ }^{\mathrm{P} 49}$ embryos, the incomplete expressivity of the mutant phenotype is evident in different hemisegments and is characterized by duplication of FDO1 $(\mathrm{B})$, loss of the two EPC $(\mathrm{C}, *)$, and duplication of the FDA 1 (D). (E-F') The opposite phenotype is found in $\mathrm{nb}^{3}$ embryos: Two FEPCs are detected at early stage 12, which are enlarging to divide (E), and no putative FDA 1 and FDO1 are detected that express Eve and/or Kr. At mid-stage 12, extra EPCs are detected $\left(F^{\prime}\right)$. $\left(F, F^{\prime}\right)$ Two different focal planes of the same mutant hemisegment at mid-stage 12. (F) The FDA 1 (yellow cells) is losing Eve and $\mathrm{Kr}$ expression; likewise $\mathrm{Kr}$ expression is decaying in both siblings produced by division of P17 (arrows). (G) The characteristic pattern of EPC and precursors of DA 1 and DO 1 in a wild-type embryo at stage 14 . (H) In an insc ${ }^{\text {P49 }}$ embryo, loss of EPC $\left(^{*}\right)$ and duplication of the precursors of muscles DA 1 (yellow syncytia, arrows) and DO1 (green syncytia, arrows) are evident. (I) The opposite phenotype is observed in a $\mathrm{nb}^{3}$ embryo: extra EPCs and the absence of DA1 and DO1 muscle precursors.

bryos exhibit these phenotypes at a higher expressivity (Table 1). These results suggest that nb acts downstream of insc, consistent with our previous data showing that insc is requi red for wild-type $\mathrm{N} b$ local ization (see Fig. 5), whereas Insc localization does not depend on nb (data not shown).

\section{Discussion}

We have analyzed the progenitor cell divisions of three mesodermal lineages that generate muscle (and pericardial cell) founders. Our results show that the final stages of the patterning of the somatic mesoderm involve the asymmetric division of progenitor cells, which gives rise to daughter cells that are intrinsically different from each other at birth. This asymmetry is effected in the progenitor by insc and is transmitted to the daughters through the asymmetric localization of $\mathrm{Nb}$ in the progenitor and, consequently, its segregation into only one daughter. Although both siblings initially express identical markers, this apparent similarity in sibling myoblast identity is short-lived and marker expression is retained in only one cell. By following the fate of three daughters that maintain marker expression, we show that they become founders for a subset of larval somatic muscles and pericardial cells. Loss of insc or nb perturbs the inherent asymmetry in the lineage and causes duplication or loss of these mesodermal structures. These findings demonstrate that the initial patterning of the somatic mesoderm through the selection of the progenitors is elaborated upon by the asymmetric division of these cells. The involvement of insc and $\mathrm{nb} / \mathrm{N}$ (this study; Ruiz-Gomez and Bate 1997) suggests that extrin- sic and intrinsic cues both play a role in the determination of founder cell fate in the mesoderm.

Sibling progeny of muscle progenitors adopt al ternative cell fates

The complex array of $\sim 30$ different muscles present in each hemisegment of the Drosophila larva is seeded by the specification of unique muscle founder cells at precise locations in the undifferentiated somatic mesoderm (Bate 1990). The first sign of patterning in the somatic mesoderm is the formation of "promuscle" clusters, defined by the expression of the gene, I'sc, within the domain of high twi expression (Carmena et al. 1995). In addition to I'sc, each cluster expresses a characteristic combination of transcription factors commonly referred to as identity genes (this paper; Carmena et al. 1995). Evidence exists indicating that the appearance of promuscle clusters at precise times and positions with specific patterns of gene expression is largely controlled by the concerted action of different positional signals emanating from the overlying neuroectoderm (A. Carmena, F. Jiménez, and A. Michelson, in prep.). A uniquely specified progenitor cell is subsequently singled out from each cluster, in a process involving lateral inhibition mediated by the Delta (DI)/N signaling pathway (Corbin et al. 1991; Bate et al. 1993; Carmena et al. 1995). Larval muscle founders as well as precursors of adult muscles are born as pairs of myoblasts produced by the di vision of muscle progenitors (Carmena et al. 1995). Such pairs of progeny cells also include, as shown here, the precursor of a pair of pericardial cells-it is therefore interesting to note that although Twi can function as a myogenic 
switch (Baylies and Bate 1996), the high Twi-expressing domains are not restricted to forming only myogenic lineages. These observations pose the question of how two different fates are adopted by each pair of sibling cells derived from a single mesodermal lineage.

Shortly after they are born, both sibling myoblasts derived from the division of a muscle progenitor usually express the same set of identity marker genes previously expressed by their progenitor. However, as the siblings mature they begin to display distinct characteristics, one of which is that for each particular marker, its expression is (usually) lost from one sibling. This results in each progeny cell expressing a different subset, complementary to that of its sibling cell, of the identity genes that characterized their common progenitor (this paper; Carmena et al. 1995; A. Carmena and F. Jiménez, unpubl.). By following the fate of sibling cells derived from the division of three progenitors, P2, P15, and P17, we have shown that the ability of sibling cells to acquire distinct cellular identities appears to be lost in embryos lacking insc. Thus, in the absence of insc, the P15 (and P17) cell division produces progeny that adopt the same identity, that of the FDA 1 (and FDO1) at the expense of its sibling, leading to the duplication of the $\mathrm{Eve}^{+} \mathrm{Kr}^{+} \mathrm{DAl}$ (and DO1). In the case of P2 cell divisions, both progeny cells appear to adopt the identity of the FEPCsib, at the expense of the FEPC, in the absence of insc; this leads to the loss of EPC.

How does insc act to promote distinct sibling myoblast cell fates? Several observations presented here strongly support the idea that insc mediates its effects in the mesoderm through the asymmetric segregation of $\mathrm{Nb}$ and the subsequent effect of $\mathrm{Nb}$ upon $\mathrm{N}$ signaling. Firstly $\mathrm{nb}$ is involved in sibling cell fate choice in the mesoderm. When its function is limiting, siblings from progenitor cell divisions take on similar characteristics. However, nb loss of function produces the opposite cell fate transformation compared to insc loss of function, that is, duplication of FEPC (gain of EPC) as well as duplication of FDA1sib and FDO1sib (loss of DA1 and DO19). Second, $\mathrm{Nb}$ is asymmetrically localized in muscle progenitors and segregates preferentially to the cell that is lost in nb mutants and duplicated in insc mutants. Furthermore, this asymmetric localization and segregation of $\mathrm{Nb}$ requires insc. Because $\mathrm{nb}$ is known to act upstream of $\mathrm{N}$ to inhibit $\mathrm{N}$ signaling for the resolution of alternative sibling cell fates in the nervous system (Guo et al. 1996; Spana and Doe 1996), our results (and those of Ruiz-Gomez and Bate 1997) suggest that the $\mathrm{N}$ signaling pathway is similarly involved in the process of generating distinct founder cell fates in the mesoderm.

Distinguishing features of the muscle progenitor cell division

Although insc has been shown previously to be required for the localization of proteins like $\mathrm{N} \mathrm{b}$ and Pros in the neuroblasts of the segmented CNS and ectodermal cells in a procephalic mitotic domain, a clear role for insc in specifying the fate of the progeny of these cells has not been demonstrated. In the PNS, it is not even clear whether insc is required for the asymmetric localization of $\mathrm{N} \mathrm{b}$ in sensory organ precursors, as $\mathrm{Nb}$ crescents still form in the absence of insc (Kraut et al . 1996). Therefore, this anal ysis of its mesodermal phenotype represents the first demonstration that insc, through its actions on the the localization and segregation of $\mathrm{Nb}$, plays a role in determining the alternative fates of sibling myoblasts (and possibly, by extension, to sibling cells in other tissues). Similar conclusions have also been reached from the anal yses of muscle progenitors in which the ul timate fates of both progeny myoblasts are known (Ruiz-Gomez and Bate 1997).

Another distinguishing feature of the muscle progenitor cell division is that the Insc and $\mathrm{Nb}$ crescents, although localized on opposite sides of the cell, are not localized in a fixed orientation, implying that these cells do not divide with a fixed orientation. This is in contrast to the neuroblasts and the Insc-expressing cells of the procephalic region that always localize Insc as apical crescents and $\mathrm{Nb}$ as basal crescents and always divide with their mitotic spindle oriented in an apical/basal orientation (Kraut et al. 1996). We speculate that this difference may be a reflection of the fact that the location of the progeny of muscle progenitors need not be controlled as strictly as those of the neuroblast cell division. One possible reason for the less stringent spatial regulation may be that muscle founders can communicate their informational content through fusion with other "naive" myoblasts. A second rationalization is that the muscle progenitors divide once, whereas the neuroblasts undergo repeated cell divisions so the requirements for positioning of the sibling progeny are different for the two cases.

The incomplete expressivity of the $\mathrm{nb}$ and insc mesodermal phenotypes

One striking feature of the phenotypes for apparent amorphic alleles of either insc or nb is that their severity not only varies widely for different muscles but also never occurs with complete expressivity for any given muscle. Although there are a number of possible influences that may contribute to this effect, we consi der two types of models/explanations that are not mutually exclusive. First, we consider the possibility that sibling myoblast fates are mediated through the superimposition of an extrinsic process mediated by $\mathrm{DI} / \mathrm{N}$ and an intrinsic process mediated by $\mathrm{N} b$, making the argument that the removal of the intrinsic factor or the failure to asymmetrically partition this factor can be partially compensated through the actions of the extrinsic process. Second, as an alternative explanation, we present arguments supporting the notion that there may be another, as yet unidentified, intrinsic factor(s) whose function overlaps that of $\mathrm{nb}$.

In the model shown in Figure 7, which represents a refinement of models proposed previously to account for progenitor cell divisions in the PN S (e.g., Posakony 1994; 
A

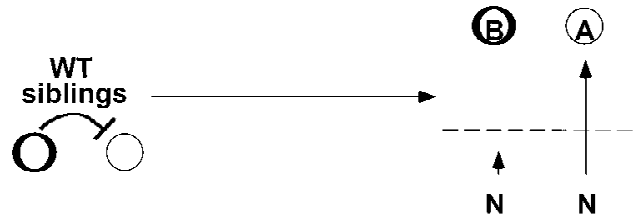

B
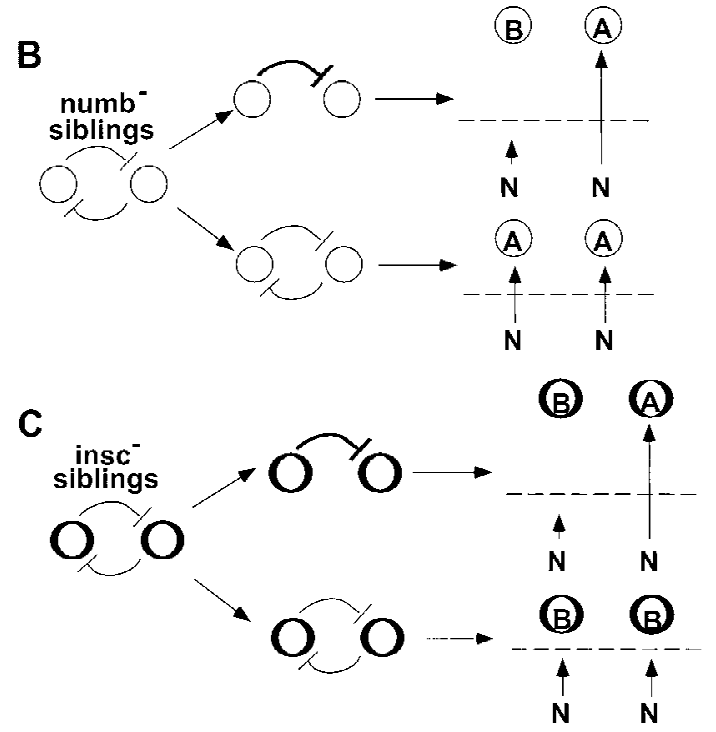

Onumb ${ }^{+} \bigcirc$ numb $^{-}$

Figure 7. A model to explain the phenotypes of $n b$ and insc loss of function. (A) In wild type (WT) sibling pairs, the presence of $\mathrm{N} \mathrm{b}$ in only one cell ensures a sufficiently large difference in $\mathrm{N}$ signaling between the two cells such that the feedback mechanism mediated by N / DI al ways becomes irreversible (see text). As a consequence, the level of $\mathrm{N}$ signaling (represented by vertical arrows) is maximal in the $\mathrm{N} \mathrm{b}^{-}$cell and minimal in the $\mathrm{N} \mathrm{b}^{+}$cell. Because the level of $\mathrm{N}$ signaling exceeds the necessary threshold (broken line) in the $\mathrm{N} \mathrm{b}^{-}$cell, it adopts an A-type fate; its $\mathrm{N} \mathrm{b}^{+}$sibling adopts the B-type fate because its level of $\mathrm{N}$ signal ing falls bel ow the threshold required for an A-type fate. In this context, where $B$ represents the primary fate, FDA 1 , FDO1, and FEPCsib cells all have B-type fate. (B) In $\mathrm{nb}^{-}$siblings a sufficiently large difference in the level of $\mathrm{N}$ signaling is not guaranteed, as neither cell inherits functional $\mathrm{N}$ b. $\mathrm{N}$ everthel ess, the N / D I feedback mechanism can become irreversi ble some of the time (see text). When this happens (top alternative) a wildtype situation ensues. However, if a sufficiently large difference in $\mathrm{N}$ signaling never arises and the feedback mechanism is never resolved (bottom alternative), the default level of $\mathrm{N}$ signaling in both cells is sufficiently above the postulated threshold required to specify an A-type fate. (C) Both sibling cells in insc ${ }^{-}$embryos are $\mathrm{N} \mathrm{b}^{+}$due to the failure of mutant progenitors to asymmetrically localize and segregate $\mathrm{N}$ b. Hence, the difference in the level of $\mathrm{N}$ signaling required to irreversibly resolve the feedback mechanism can only arise through stochastic variations (top al ternative) and statistically this will occur only a proportion of the time. When this fails (bottom alternative), the default level of $\mathrm{N}$ signaling in the siblings (due to the presence of $\mathrm{Nb}$ in both cells) falls below the threshold required to specify an A-type fate and both cells adopt the default B-type fate.
Jan and Jan 1995), two sibling myoblasts are born initially with equivalent levels of $\mathrm{N}$ inhibitory signal that are sufficient to inhibit the primary fate (fate B). However, stochastic variati ons may eventually cause one cell (cell A) to transiently acquire a higher amount of $\mathrm{N}$ inhibitory signal. This would lead to decreased DI expression in cell $\mathrm{A}$, thereby decreasing $\mathrm{N}$ signaling in the sibling cell B. Consequently, cell B will produce more DI, thereby increasing its capacity to inhibit cell A. Ultimately, if a sufficiently large difference in the level of $\mathrm{N}$ signaling can be attained via this feedback mechanism, this process will become irreversibly unidirectional; cell $A$ will end up receiving a high level of $N$ inhibitory signal and adopt the secondary fate (fate A), and its sibling will receive a low level of $\mathrm{N}$ signal and adopt the primary fate $B$.

Under normal circumstances $\mathrm{Nb}$ is asymmetrically partitioned to one of the sibling cells, creating a large initial difference in $\mathrm{N}$ signaling to ensure that the feedback mechanism ensues and that distinct sibling cell fates can al ways be resolved. However, even when $\mathrm{N}$ b is absent (nb- mutant) or similarly distributed to both sibling cells (in insc ${ }^{-}$mutants or in the Gal4-driven overexpression strategy used to ectopically express $\mathrm{Nb}$ in both sibling cells), the feedback mechanism can still ensue leading to the resol ution of distinct sibling cell fates, al beit in only a fraction of the cases. In such cases, normal fates are still realized $(A+B)$, accounting for the incomplete expressivity of the mutant phenotypes. In the remaining cases, where the feedback mechanism fails to become irreversible and does not resolve al ternative sibling fates, the outcome depends on the genotype of the sibling myoblasts. Thus, in $\mathrm{nb}^{-}$mutants, the initial high level of $\mathrm{N}$ inhibitory signaling in both cells is maintained inhibiting the primary fate $B$ (thus resulting in $A+A$ ). In contrast, in insc ${ }^{-}$mutants or under uniform overexpression of $\mathrm{nb}$, the presence of $\mathrm{Nb}$ in both cells is sufficient to reduce the level of inhibitory $\mathrm{N}$ signaling below the threshhold required to inhibit primary fate $B$ (thus resulting in $B+B$ ). The frequency by which the mutual inhibition mediated by $\mathrm{DI} / \mathrm{N}$ can be resolved in the different mutant genotypes may be context-dependent, thereby resulting in different degrees of cell fate transformation depending on the particular pair of sibling cells being considered.

It is also interesting to reflect on the observation that the mesodermal phenotype of the nb/insc double mutant, although qualitatively similar to that of the $\mathrm{nb}$ single mutant, is more severe than that of the nb single mutant for structures derived from all three progenitors used for this study (see Table 1). This increased severity in the double mutant might be attributable to the effect imposed (as the result of loss of insc) by the lack of asymmetric segregation of an as yet unidentified factor(s), which normally is also asymmetrically localized and segregated under the control of insc and which overlaps the function of nb during myogenesis. It may al so be that this postulated factor is the maternal component of $\mathrm{N} \mathrm{b}$. The incomplete expressivity of the loss-of-function phenotypes of $\mathrm{nb}$ and insc as well as the gain-of-function 
phenotype of $\mathrm{nb}$ can be readily accounted for by either (or a combination) of the explanations/models discussed here.

\section{Materials and methods}

\section{Drosophila strains}

The insc excision alleles, insc ${ }^{\mathrm{P} 49}$ and insc ${ }^{\mathrm{P} 72}$ (Kraut and Campos-Ortega 1996), the original P-lacZ insertion at the insc locus, $A B 44$, which served as a control and the hsp70-insc and insc ${ }^{\text {P49 }}$ $\mathrm{nb}^{3}$ stocks were made by Rachel Kraut when she was in the Chia laboratory. We believe that insc ${ }^{\mathrm{P} 49}$ and insc $\mathrm{P}^{\mathrm{P} 2}$ are nulls because no Insc protein crescents are seen in the mutant embryos. The putative amorphic numb alleles, $\mathrm{nb}^{1}$ and $\mathrm{nb}^{3}$, as well as the UAS-nb lines were gifts of the Jans laboratory (U emura et al. 1989; Rhyu et al. 1994). The homozygous viable twi-gal4 driver (on the X chromosome) was obtained from Michael Akam (University of Cambridge, UK).

\section{Immunochemical staining of whole-mount embryos}

Embryos were fixed and stained as described previously (M urugasu-Oei et al. 1995). The staining reaction (Hsu et al. 1988) was devel oped using secondary anti bodies conjugated to horseradish peroxidase with diaminobenzidine substrate, in the presence (black) or absence (brown) of nickel ions. Immunofluorescence embryos were fixed and stained according to Carmena et al. (1995). DN A was visualized using $1 \mathrm{mg} / \mathrm{ml}$ of sonicated paraphenylene-diamine (Sigma) in 90\% glycerol (Lundell and Hirsh 1994). Embryos were observed under $\mathrm{N}$ omarski optics, whereas confocal images were viewed using a Zeiss microscope equipped with a BioRad M RC 600 laser and processed using Adobe Photoshop software. Embryos were staged according to CamposOrtega and Hartenstein (1985). Muscle nomenclature follows Bate (1993).

The following primary antibodies were used: anti- $\beta$-galactosidase (rabbit from Cappel, 1:10,000; mouse from Promega, 1: 500), a mouse anti-Eve monocl onal (2B8, 1:60; Patel et al. 1994), a rabbit anti-Eve (1:1000; Frasch et al. 1987), mouse anti-Insc (1:1000; Kraut et al. 1996), rabbit anti-Insc (1:2000), rabbit anti$\operatorname{Kr}$ (1:1500; a gift from Helen Skaer, U niversity of Sheffield, UK), rat anti-L'sc (1:400; Martín-Bermudo et al. 1991), mouse antiMyosin heavy chain (1:80; Kiehart and Feghali 1986), rabbit anti-N b (1:1000; Rhyu et al. 1994), and rabbit anti-Twi (1:5000; a gift from Maria Leptin, University of Köln, Germany).

\section{Ectopic expression and rescue experiments}

For the insc rescue experiment, the stock insc $\mathrm{P}^{\mathrm{49}} / \mathrm{CyO} \mathrm{P}[\mathrm{ftz}-$ lacZ]; hsp70-insc/TM3 Sb P[U bx-lacZ] was constructed. Double homozygotes were recognized by the lack of $\beta$-galactosidase expression. For the heat shock treatment, embryos were collected at $16^{\circ} \mathrm{C}$ overnight, dechorionated, submerged in preheated phosphate-buffered saline containing $0.01 \%$ Triton$\mathrm{X} 100$, and placed in a $37^{\circ} \mathrm{C}$ water bath for 10-15 min. Embryos were aged for 8-9 hr, fixed, and stained, and stage 15-16 embryos were scored, or processed within 1-2 hr following heat shock. Control wild-type or hsp70-insc animals treated as above showed normal muscle patterns.

To express nb ectopically, homozygous twi-gal 4 virgins were mated to homozygous UAS-nb mal es to generate embryos each carrying a single copy of the driver and the UAS-nb.

\section{Acknowledgments}

Wethank Michael Akam, José Campos-Ortega, M anfred Frasch, Y uh N ungJan, Dan Kiehart, M aria Leptin, Helen Skaer, and Kai Zinn for flies and antibodies; Mike Bate for exchanging information prior to publication; Rachel Kraut, Sami Bahri, Marita Buescher, and Xioahang Y ang for advice and hel p; Kathleen Tan for technical assistance; and members of the Jiménez and Chia laboratories for discussion and comments on the manuscript. A.C. held a fellowship from the Spanish MEC. This work was supported by IMCB and European Community (EC) grants to W.C. and by grant PB93-0099 from DGICYT to F.J.

The publication costs of this article were defrayed in part by payment of page charges. This article must therefore be hereby marked "advertisement" in accordance with 18 USC section 1734 solely to indicate this fact.

\section{References}

Artavanis-Tsakonas, A., K. Matsuno, and M.E. Fortini. 1995. N otch signaling. Science 268: 225-232.

Baker, R. and G. Schubiger. 1995. Ectoderm induces musclespecific gene expression in Drosophila embryos. Development 121: 1387-1398.

Bate, M. 1990. The embryonic devel opment of larval muscles in Drosophila. Development 110: 791-804.

-_- 1993. The mesoderm and its derivatives. In The development of Drosophila melanogaster (ed. M. Bate and A. M artínez-A rias), pp. 1013-1090. Cold Spring Harbor Laboratory Press, Cold Spring Harbor, NY.

Bate, M., E. Rushton, and M. Frasch. 1993. A dual requirement for neurogenic genes in Drosophila myogenesis. Development (Suppl.) pp. 149-161.

Baylies, M.K., A. Martínez-Arias, and M. Bate. 1995. wingless is required for the formation of a subset of muscle founder cells during Drosophila embryogenesis. Development 121: 38293837.

Baylies, M.K. and M. Bate. 1996. twist: A myogenic switch in Drosophila. Science 272: 1481-1484.

Bourgouin, C., S.E. Lundgren, and J.B. Thomas. 1992. apterous is a Drosophila LIM domain gene required for the devel opment of a subset of embryonic muscles. Neuron 9: 549-561.

Brand, A. and N. Perrimon. 1993. Targeted gene expression as a means of altering cell fates and generating dominant phenotypes. Development 118: 401-415.

Broadie, K. and M. Bate. 1993. M uscle devel opment is independent of innervation during Drosophila embryogenesis. Development 119: 533-543.

Burchard, S., A. Paululat, U. Hinz, and R. Renkawitz-Pohl. 1995. The mutant not enough muscles (nem) reveals reduction of the Drosophila embryonic muscle pattern. J. Cell Sci. 108: 1443-1454.

Campos-Ortega, J.A. and V. Hartenstein. 1985. The embryonic development of Drosophila melanogaster. Springer-Verlag, Berlin, Germany.

Carmena, A., M. Bate, and F. Jimenez. 1995. lethal of scute, a proneural gene, participates in the specification of muscle progenitors during Drosophila embryogenesis. Genes \& Dev. 9: 2373-2383.

Corbin, V., A.M. Michelson, S.M. Abmayr, V. N eel, E. Alcamo, T. Maniatis, and M.W. Young. 1991. A role for the Drosophila neurogenic genes in mesoderm differentiation. Cell 67: 311-323.

Dohrmann, C., N. Azpiazu, and M. Frasch. 1990. A new Drosophila homeo box gene is expressed in mesodermal precursor cells of distinct muscles during embryogenesis. Genes \& 
Dev. 4: 2098-2111.

Dunin Borkowski, O.M., N.H. Brown, and M. Bate. 1995. Anterior-posterior subdivision and the diversification of the mesoderm in Drosophila. Development 121: 4183-4193.

Frasch, M. 1995. Induction of visceral and cardiac mesoderm by ectodermal Dpp in the early Drosophila embryo. Nature 374: 464-467.

Frasch, M., T. Hoey, C. Rushlow, H. Doyle, and M. Levine. 1987. Characterisation and localisation of the even-skipped protein of Drosophila. EMBO J. 6: 749-759.

Guo, M., L.Y. Jan, and Y.N . Jan. 1996. Control of daughter cell fates during asymmetric division: interaction of $\mathrm{Numb}$ and N otch. Neuron 17: 27-41.

Hirata, J., H. N akagoshi, Y. N abeshima, and F. M atsuzaki. 1995. Asymmetric segregation of a homeoprotein, prospero, during cell division in neural and endodermal development. Nature 377: 627-630.

Hsu, S., G. Ju, and L. Fan. 1988. The glucose-oxidase-nickel method in peroxidase histochemistry of the nervous system. Neurosci. Lett. 85: 169-171.

Jan, Y.N . and L.Y. Jan. 1995. M aggot's hair and bug's eye: role of cell interactions and intrinsic factors in cell fate specification. Neuron 14: 1-5.

Kiehart, D.P. and R. Feghali. 1986. Cytoplasmic myosin from Drosophila melanogaster. J. Cell Biol. 103: 1517-1525.

Knirr, S., S. Breuer, A. Paululat, and R. Renkawitz-Pohl. 1997. Somatic mesoderm differentiation and the development of a subset of pericardial cells depend on the not enough muscles (nem) locus, which contains the inscuteable gene and the intron located gene, skittles. Mech. Dev. 67: 69-81.

Knoblich, J.A., L.Y. Jan, and Y.N. Jan. 1995. Localisation of numb and prospero reveal s a novel mechanism for asymmetric protein segregation during mitosis. Nature 377: 624-627.

Kraut, R. and J.A. Campos-Ortega. 1996. inscuteable, a neural precursor gene of Drosophila, encodes a candi date for a cytoskel eton adaptor protein. Dev. Biol. 174: 65-81.

Kraut, R., W. Chia, L.Y. Jan, Y.N. Jan, and J.A. Knoblich. 1996. Role of inscuteable in orienting asymmetric cell divisions in Drosophila. Nature 383: 50-55.

Li, P., X. Yang, M. Wasser, Y. Cai, and W. Chia. 1997. Inscuteable and Staufen mediate asymmetric localisation and segregation of prospero RNA during Drosophila neuroblast cell divisions. Cell 90: 437-447.

Lundell, M.J. and J. Hirsh. 1994. A new visible light DN A fluorochrome for confocal microscopy. BioTechniques 16: 434440.

Martín-Bermudo, M., C. Martínez, A. Rodríguez, and F. Jiménez. 1991. Distribution and function of the lethal of scute gene product during early neurogenesis in Drosophila. Development 113: 445-454.

Michel son, A.M., S.M . Abmayr, M. Bate, A. M artínez-Arias, and T. Maniatis. 1990. Expression of a MyoD family member prefigures muscle pattern in Drosophila embryos. Genes \& Dev. 4: 2086-2097.

Murugasu-Oei, B., V. Rodrigues, X. Yang, and W. Chia. 1995. $M$ asquerade: A novel secreted serine protease-like molecule is required for somatic muscle attachment in the Drosophila embryo. Genes \& Dev. 9: 139-154.

Patel, N.H., B.G. Condron, and K. Zinn. 1994. Pair-rule expression patterns of even-skipped are found in both long and short band beetles. Nature 367: 429-434.

Posakony, J.W. 1994. N ature versus nurture: Asymmetric cell divisions in Drosophila bristle development. Cell 76: 415418.

Ranganayakulu, G., R.A. Schulz, and E.N. Olson. 1996. Wingless signaling induces nautilus expression in the ventral me- soderm of the Drosophila embryo. Dev. Biol. 176: 143-148.

Rhyu, M.S., L.Y. Yan, and Y.N. Jan. 1994. Asymmetric distribution of $\mathrm{N}$ umb protein during division of the sensory organ precursor cell confers distinct fates to daughter cells. Cell 76: 477-491.

Ruiz-Gomez, M. and M. Bate. 1997. Segregation of myogenic lineages in Drosophila requires Numb. Development 124: 4857-4866.

Ruiz-Gomez, M., S. Romani, C. Hartmann, H. Jäckle, and M. Bate. 1997. Specific muscle identities are regulated by Krüppel during Drosophila embryogenesis. Development 124: 3407-3414.

Rushton, E., R. Drysdale, S.M. Abmayr, A.M. Michelson, and M. Bate. 1995. Mutations in a novel gene, myoblast city, provide evidence in support of the founder cell hypothesis for Drosophila muscle development. Development 121: 1979-1988.

Spana, E. and C.Q. Doe. 1995. The prospero transcription factor is asymmetrically localised to the cortex during neuroblast mitosis in Drosophila. Development 121: 3187-3195.

- - . 1996. N umb antagonizes $\mathrm{N}$ otch signal ing to specify sibling neuron cell fate. Neuron 17: 21-26.

Spana, E., C. Kopczynski, C.S. Goodman, and C.Q. Doe. 1995. Asymmetric localization of Numb autonomously determines sibling neuron identity in the Drosophila CNS. Development 121: 3489-3494.

Staehling-Hampton, K., F.M. Hoffman, M.K. Baylies, E. Rushton, and M. Bate. 1994. dpp induces mesodermal gene expression in Drosophila. Nature 372: 783-786.

Thisse, B., C. Stoetzel, C. Gorostiza-Thisse, and F. PerrinSchmitt. 1988. Sequence of the twist gene and nuclear localization of its protein in endomesodermal cells of early Drosophila embryos. EMBO J. 7: 2175-2183.

U emura, T., S. Shepherd, L. Ackerman, L.Y. Jan, and Y.N. Jan. 1989. numb, a gene required in determination of cell fate during sensory organ formation in Drosophila embryos. Cell 5: 349-360. 


\title{
Errata
}

Genes \& Development 11: 3265-3276 (1997)

The Xenopus Brachyury promoter is activated by FGF and low concentrations of activin and suppressed by high concentrations of activin and by paired-type homeodomain proteins

Branko V. Latinkić, M uriel U mbhauer, Kathy A. N eal, Walter Lerchner, James C. Smith, and Vincent Cunliffe

The first author's name was spelled incorrectly in this article. It is correct here.

Genes \& Development 12(6) March 15, 1998

The cover headline and caption for this issue were incorrect. The headl ine should read:

Regulation of the cell division protein FtsZ in Caulobacter.

The correct caption is printed bel ow.

Cover Caulobacter crescentus and the cell division initiation protein FtsZ through the cell cycle. Shown are electron micrographs of Caulobacter (top) and immunofluorescence analysis of FtsZ (bottom) at different stages through the cell cycle. The cell cycle initiates with a swarmer cell (left) that contains a single polar flagel lum (wavy line), which differentiates into a stalked cell (third from left) by shedding the flagellum and synthesizing a stal $k$ at the same pole. The predivisional cell (fourth from left) contains a single flagellum synthesized at the pole opposite the stalk. Cell division produces a swarmer cell and stalk cell (right). The replication-competent stalk cell contains FtsZ, whereas the replication-incompetent swarmer cell lacks FtsZ. (For details, see Kelly et al., p. 880.)

Genes \& Development 12: 782-796 (1998)

\author{
Helios, a T cell-restricted Ikaros family member that quantitatively associates with I karos at centromeric \\ heterochromatin \\ Kyungmin Hahm, Bradley S. Cobb, Aaron S. McCarty, Karen E. Brown, Christopher A. Klug, Robert Lee, \\ Koichi Akashi, Irving L. Weissman, A manda G. Fisher, and Stephen T. Smale
}

The name of Irving L. Weissman was spelled incorrectly in the Table of Contents of this issue. It is correct here.

\section{Genes \& Development 12(7)}

The cover headline and caption for this issue were incorrect. The headl ine should read: Role of CBP in C. elegans embryonic differentiation

The correct caption is printed below.

Cover Expression and phenotypic analysis of CBP-1 in Caenorhabditis elegans. Shown are $\mathrm{N}$ omarski images of wild-type (top left) and cbp-I mutant (top right) embryos. The mutant embryo produces many small cells and shows no evidence of mesodermal, endodermal, or hypodermal tissue organization. The small cells are reminiscent of neuronal cells, and immunostaining with antibodies against UNC-86, a neuronal differentiaton-specific protein, of wild-type (bottom left) and cbp-I (bottom right) reveals an increase in the number of neuronal precursors in mutant embryos. (For details, see Shi and Mello, p. 943). 


\section{Erratum}

Genes \& Development 12: 304-315 (1998)

inscuteable and numb mediate asymmetric muscle progenitor cell divisions during $D$ rosophila myogenesis Ana Carmena, Bernadette Murugasu-Oei, Devi Menon, Fernando Jiménez, and William Chia

Figure 6 of this article should have appeared in color. The correct figure and legend appear bel ow.

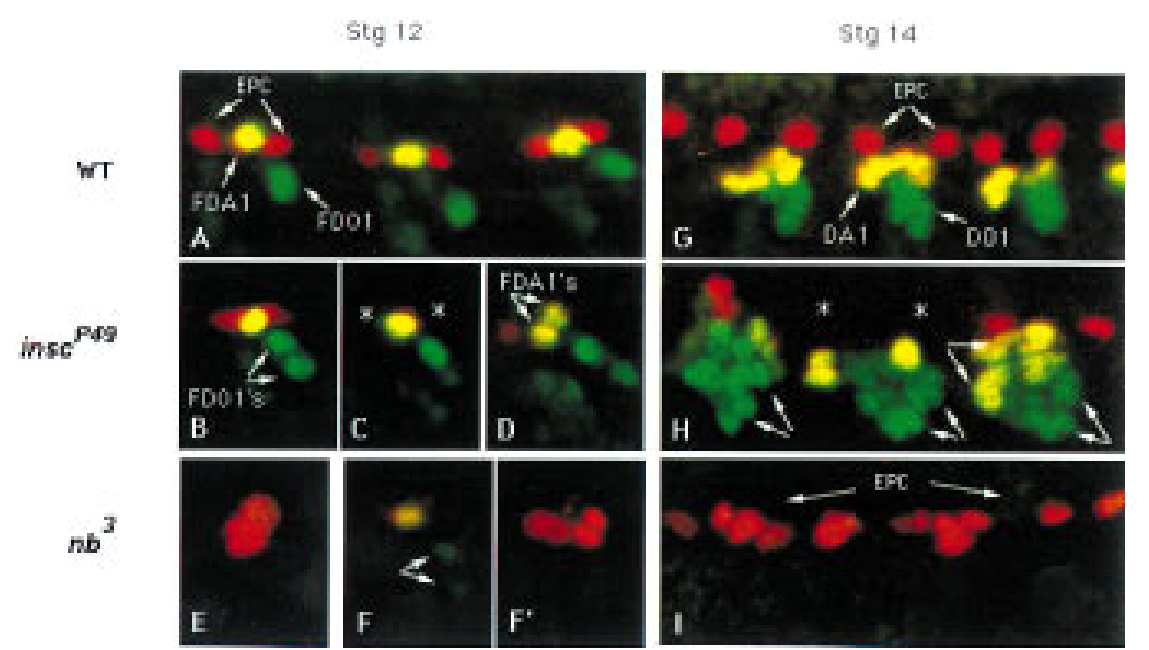

Figure 6. The fate of the progeny from $\mathrm{P} 2$, P15, and P17 progenitors in wild-type, insc $^{\text {P49, }}$, and numb ${ }^{3}$ embryos. Embryos were double stained for Eve (red) and $\mathrm{Kr}$ (green). Stage $12\left(A-F^{\prime}\right)$ and stage $14(G-I)$ wild-type $(A, G)$, insc ${ }^{P 49}(B-D, H)$, and $n b^{3}$ $\left(E-F^{\prime}, I\right)$ embryos are shown. (A) Three consecutive wild-type hemisegments at midto late-stage 12. At this stage, the two EPC (red) are already present. The $\mathrm{Kr}^{+} \mathrm{Eve}^{+}$ FDA 1 (yellow) and the $\mathrm{Kr}^{+} \mathrm{FDO} 1$ (green) are also evident. (B-D) In insc ${ }^{\mathrm{P} 49}$ embryos, the incomplete expressivity of the mutant phenotype is evident in different hemisegments and is characterized by duplication of FDO1 (B), loss of the two EPC $(C, *)$, and duplication of the FDA 1 (D). (E-F') The opposite phenotype is found in $\mathrm{nb}^{3}$ embryos: Two FEPCs are detected at early stage 12,

which are enlarging to divide (E), and no putative FDA 1 and FDO 1 are detected that express Eve and/or Kr. At mid-stage 12, extra EPCs are detected $\left(F^{\prime}\right)$. $\left(F, F^{\prime}\right)$ Two different focal planes of the same mutant hemisegment at mid-stage 12. (F) The FDA 1 (yellow cells) is losing Eve and $\mathrm{Kr}$ expression; likewise, $\mathrm{Kr}$ expression is decaying in both siblings produced by division of P17 (arrows). (G) The characteristic pattern of EPC and precursors of DA 1 and DOI in a wild-type embryo at stage 14. (H) In an insc ${ }^{\text {P49 }}$ embryo, Ioss of EPC $\left(^{*}\right)$ and duplication of the precursors of muscles DA 1 (yellow syncytia, arrows) and DO1 (green syncytia, arrows) are evident. (I) The opposite phenotype is observed in a $\mathrm{nb}^{3}$ embryo; extra EPCs and the absence of DA1 and DO1 muscle precursors. 


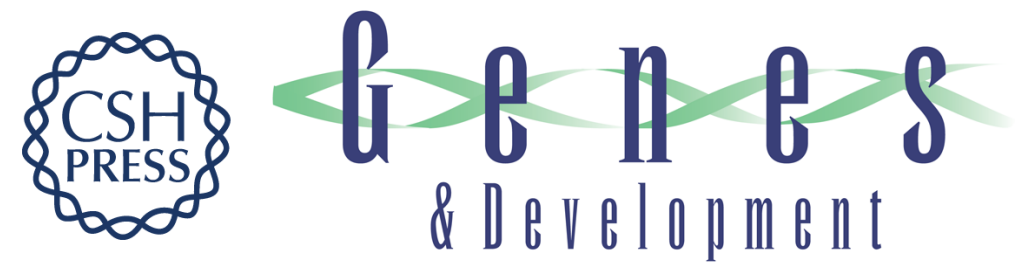

\section{inscuteable and numb mediate asymmetric muscle progenitor cell divisions during Drosophila myogenesis}

Ana Carmena, Bernadette Murugasu-Oei, Devi Menon, et al.

Genes Dev. 1998, 12:

\section{Related Content Errata for vol. 12, p. 304}

Genes Dev. April , 1998 12: 1241

References This article cites 42 articles, 20 of which can be accessed free at: http://genesdev.cshlp.org/content/12/3/304.full.html\#ref-list-1

Articles cited in:

http://genesdev.cshlp.org/content/12/3/304.full.htmI\#related-urls

\section{License}

Email Alerting

Service

Receive free email alerts when new articles cite this article - sign up in the box at the top right corner of the article or click here.

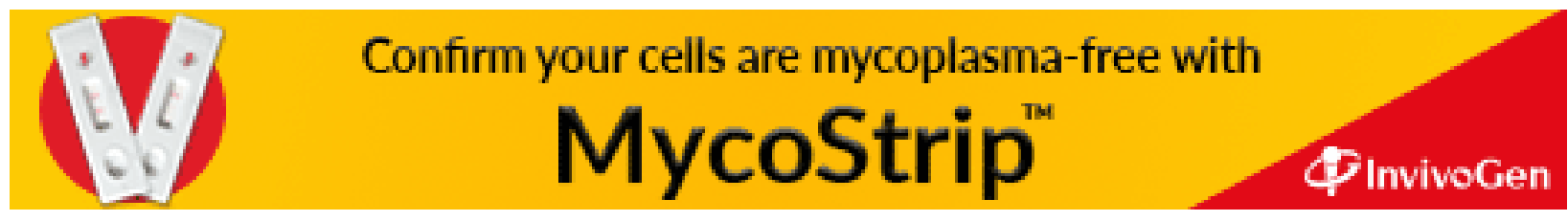

